\title{
The power of Two-Sided Platforms to disseminate Resistant
}

\author{
Innovations
}

\author{
Daniel TRABUCCHI \\ School of Management - Politecnico di Milano \\ daniel.trabucchi@polimi.it \\ Tommaso BUGANZA \\ School of Management - Politecnico di Milano \\ tommaso.buganza@polimi.it
}

Purpose: Platforms have often been considered an excellent example of innovation with an incredibly fast diffusion rate due to network effects. Notwithstanding, in many cases, they match the definition of resistant innovations, requiring a significant change in the consumers' behavior that may slow down the process of diffusion. How can network effects be leveraged to disseminate resistant innovation based on a platform structure?

Design/Methodology/Approach: This research focuses on the Car Sharing industry as a single case study, involving five different providers and two service aggregators operating in Milan, Italy.

Findings: First, this research shows how direct network externalities on the providers' side may play a vital role in the dissemination process, increasing the value perceived by the potential new entrants. Second, it shows how co-opetition dynamics, eventually encouraging multi-homing phenomenon, may play - in the first phases of the diffusion process -a pivotal role to let the industry flourish.

Research implications: This research contributes to the growing literature on platforms and two-sided platform showing how this model may be applied more broadly to network businesses to understand competitive dynamics.

Practical implications: This study offers insights to managers and practitioners dealing with network services, showing the potential benefits of coopetitive strategies while facing the initial phases of the dissemination process.

Originality/value: This paper gets together resistant innovation, two-sided platforms and network effects offering novel insights on the dynamics of network services such as the car-sharing - while giving fresh insights taking the perspective of the service providers.

This is the post-print version of the paper published on Management Decision, please cite as

Trabucchi, D., and Buganza, T. 2020. "The power of Two-Sided Platforms to disseminate Resistant Innovations", Management Decision. 10.1108/MD-06-2019-0727 


\section{Introduction}

Platforms are challenging entire industries with a disruptive impact (e.g., Downes and Nunes 2013) and stimulated much research in the management field (Gawer and Cusumano, 2014). Several cases may be used to present this phenomenon, such as Uber or Airbnb.

Scholars demonstrated the disruptive impact of these businesses. Uber reached a rough market valuation of $60-70$ \$B without owning any car and relying on more than $1 \mathrm{M}$ drivers, while Hertz a 7 \$B market valuation with 350k cars. Similar numbers for Airbnb VS Starwood or WeChat VS AT\&T (Libert et al. 2016). Downes and Nunes (2013) showed how the diffusion process of this kind of business moves from the traditional diffusion curve to a shark fin diffusion curve, with massive initial growth.

One of the key peculiarities of this phenomenon is the chance to reach a worldwide extension in a short amount of time. A phenomenon which is also known as "accelerated international expansion", studied both through various perspective (Gaur et al., 2014) and which has multiple impacts on different levels (the country to the firm and the individual levels Gaur et al., 2019) highlighting the link between the governance structure and the internationalization (Singh and Gaur, 2013). In other words, platforms have a peculiar internal resource structure: they do not rely on internal resources to grow (Amit and Han, 2017), having the chance to go through this accelerated expansion, as Uber had, for example (Bugador, 2019).

This kind of companies can scale up, both in terms of users and in terms of value, since they do not directly need to own the physical assets to offer the service, they act as intermediaries (Ndubisi et al., 2016) Therefore, platforms are making the diffusion process of an innovation something faster and more pervasive, leveraging different kinds of network externalities (Katz and Shapiro 1985) that let these companies exponentially grow once the critical mass is reached (Economides and Himmelberg 1995). Notwithstanding, some innovations suffer notably the first launch on the market, since they aim to change a dominant 
status quo in the behaviors of the consumers, they are defined as resistant innovations (Ram and Sheth 1989). Scholars studying this kind of innovation proposed the chance to leverage network effects as one of the possible strategies to overcome the initial resistance, letting the diffusion process start (Garcia et al. 2007).

Since network effects have a significant impact once the critical mass is reached, can they help in disseminating a resistant innovation?

The concept of resistant innovation is directly related to the changes in typical consumers' behavior, which is particularly prevalent in several platforms. For example, the introduction of eBay was received by many potential consumers with skepticism due to the chance to buy - digitally - from someone who is not a professional seller. So, how can companies leverage platform mechanisms to activate network effects to disseminate a resistant innovation?

\section{Literature review}

\subsection{Diffusion and dissemination of innovations}

One of the most relevant streams of research in the innovation field deals with the diffusion of innovation. Two main actors have a crucial role in the diffusion process: the users and the innovating entities which propose the innovation (Rogers 2010), giving birth to two main dynamics: pure diffusion and active dissemination (Greenhalgh et al. 2004). The inability to understand and to manage the differences between these two dynamics may be fatal for the innovation launch. Indeed the market introduction phase may destroy how the market perceives the innovation itself (Frattini et al. 2013).

The diffusion process is mainly passive, leveraging mechanisms such as contagion and imitation (Greenhalgh et al. 2004). One of the most famous models to explain the diffusion 
process has been proposed by Rogers showing the characteristics of the different clusters of people in the diffusion process (i.e. innovators, early adopters, early majority, late majority and laggards) as well as the drivers of different rate adoptions from the users' perspective (i.e. relative advantage, compatibility, complexity, trialability and observability (Rogers 2010).

On the other hand, the dissemination process is a planned and active process where companies play a crucial role, aiming to increase the rate and the level of adoption (Greenhalgh et al. 2004). Interestingly, $R \& D$ - business development - and marketing capabilities need to be considered in an integrated way to enhance the dissemination process (Ali et al., 2018).

The concept of dissemination relies on the idea that the market is quite never ready to accept and innovation, in particular for radical and complex innovations. Therefore, this process is mainly related to the chance to identify a clear and effective strategy to present innovation in the best way (Hultink et al. 1997; Magistretti et al., 2020, Artusi and Bellini, 2020).

Focusing on the second dynamic, we would focus on the role of divergent networks. They are defined as interfirm networks in which companies along the supply and value chains collaborate to develop innovations (Dittrich and Duysters 2009) involving complementors and external organization until the launching phase decrease the risk of non-adoption and expand endorsement possibilities (Frattini et al. 2013).

\subsection{Resistant innovations}

Considering the diffusion and the dissemination processes of innovation, it is relevant to consider a particular kind of innovations that face even more significant challenges along with these processes.

Resistant innovations have been defined as products or services that make potential changes on a satisfactory status quo or that go against the consumers' current beliefs (Ram and 
Sheth 1989). They can be considered the opposite pole of receptive innovation, defined as innovations that get easily welcomed by the market since they do not require changes in behaviors or traditions (Garcia et al. 2007). Therefore, adoption and diffusion happen when customers overcome resistance (Szmigi and Foxall 1998).

Resistant innovations can also be considered a subset of the broader category of discontinuous innovation - those that cause a discontinuity in the existing market due to features or attributes that are radically new to the market (Garcia and Calantone, 2002).

The main characteristics of resistant innovations are the lag in the timing adoption, its severity degree and its existence across product classes (Ram and Sheth 1989). The antecedents to resistance may be classified into two main clusters: functional barriers - considering usage, value and risk barriers - and physiological barriers - considering tradition and image barriers (Ram and Sheth 1989).

Garcia and colleagues suggest a few strategies to overcome resistance and disseminate resistant innovation. In particular, they focus on cooperation along the supply chain and coopetition dynamics (Garcia et al. 2007).

Coopetition is a matter of "partially convergent interest (and goal) structure where both competitive and cooperative issues are simultaneously present and strictly interconnected. [...] The co-opetitive perspective stresses that the supreme interests of a partner are not necessarily aligned with the supreme interest of the other partner(s)" (Dagnino \& Padula, 2002, p. 9).

The concept of coopetition gains particular importance in the context of a networked economy, as the traditional "winner-take-all" logic is giving way to a realization that companies must cooperate and compete (Bowser, 2001). 


\subsection{Network effects}

Some products and services have a peculiar diffusion path. Network goods have been highly studied for their ability to have an exponential diffusion once the critical mass is reached (Economides and Himmelberg 1995). Network goods are defined through the existence of network externalities, which link the utility, the value of the good itself, with is adoption (Katz and Shapiro, 1985). In particular, two main types of externalities are defined: direct (the value of the good increases with an increase in the number of adopters, typical examples are the telephone or social networks) and indirect (the utility for users A depends on the number of users B, a typical example is the credit card market, having cardholders and merchants accepting the card) (Katz and Shapiro 1985; Hagiu and Wright 2015).

In the introduction, we mentioned the phenomenon of accelerated business expansion. It is relevant to highlight how the literature on multinational companies relied on the concept of network to highlight peculiar characteristics. Indeed, multinational companies tend to build strong networks among the original company and all the subsidiaries aiming to enhance the innovation process and spreading knowledge to all the parties, increasing the company's' success (Nuruzzaman et al., 2019). This may also mean reducing the traditional authority of the original company, shifting towards a hub model, but this increases the efficiency (Lunnan and McGaughey, 2019). The chance to rely on a strong network, also represented by the employees, through their relationship, increase the effectiveness and efficiency of these companies (Pedersen et al., 2019). This needs to take into account the peculiarity of a single country (Maharjan and Sekiguchi, 2017).

Recently, the attention to these topics increased due to the diffusion and relevance of new business models that leverage this kind of mechanism. Studies on two-sided platforms expanded the knowledge on businesses that rely on the existence of indirect network 
externalities between two groups of customers (e.g., Rochet and Tirole 2003, Trabucchi et al., 2019), such as drivers and users in the above-mentioned case of Uber.

Even if network goods have, by definition, a particular path in the diffusion process, adoption research has mostly ignored them (Beck et al. 2008). According to Beck and colleagues, network effects add a new dimension to the decision-making process to facilitate the diffusion and dissemination of innovation. Their study shows how there is a high interdependence between direct and indirect network effects that influence the adoption of the diffusion rate (Beck et al. 2008).

One of the drivers of competition in this kind of market is the chance for a customer to be on different platforms at the same time, defining the concept of multi-homing (Amstrong 2006). If one of the two sides may multi-home, while the second is forced to be single-home, there is a competitive bottleneck (Amstrong and Wright 2007). The primary strategy to avoid the multi-homing effect is to differentiate as much as possible the offer from other competitors (Gawer and Cusumano 2014).

Therefore the aim of this study: deep in the relationship between the diffusion (considering both pure diffusion and dissemination) and network effects. Indeed, previous studies suggest the chance to leverage network effects to foster a good diffusion strategy, but there is a lack of clarity regarding the implications of this decision. In particular, we aim to understand how these dynamics may be suitable to foster the diffusion of a resistant innovation.

How can companies rely on network effects to disseminate a resistant innovation?

\section{Research design and method}

The car-sharing industry is considered a resistant innovation since it challenges a robust cultural paradigm: car ownership (Cohen \& Kietzmann, 2014). The idea to often use a car that is not "owned" requires a profound change in the status quo and the users' behavior (think about the 
emotional attachment to the car). Moreover, car sharing has already been considered a case of resistant innovation in the literature (Claudy et al. 2015). Furthermore, car sharing meets the requirement to be defined as a network good. The utility to join the service is directly linked with the number of cars spread across the city, indeed increase the number of cars will increase the chance to have one close enough to be rent (bringing to a higher utility). At the same time, a more significant number of final users will increase the utility of adding other cars in the city. This mechanism perfectly matches the indirect network externalities, as defined by Katz and Shapiro (1985).

\subsection{Empirical setting and sampling}

This research considers the car-sharing industry in Milan (Italy) since it represents one of the most advanced European cities concerning shared mobility through a certain number of established flee-floating and stationery based providers (Schiller et al., 2017), due to the high number of players involved. Car sharing was first introduced in 2000 through a public intervention aiming to develop and promote sustainable and innovative mobility services. Then, starting in 2013, different private players approached the market, creating a competitive scenario that has been particularly complex. Five operators are active in the municipality, and some of them use the city to firstly propose innovations that to be later expanded to other countries.

Our research is based on a single case study, an approach justifiable for theory development when there is little prior theory relating to the research phenomenon (Eisenhardt, 1989), coherently with previous research (e.g., Arbussa et al., 2017). The use of a single case study fosters an in-depth understanding of the phenomenon.

According to Siggelkow (2007), the existence of a phenomenon can be described by a single case study, which is also considered better than multiple cases to produce extra and better theory in exploratory research (Dyer and Wilkins, 1991). This is even more important in cases in which 
the unit of analysis is made of a group of actors (Yin, 2003). This is the case we are observing since it is related to the actions of different kinds of companies operating in the same market and influencing one the others with their strategic choice in terms of dissemination. Therefore, the chance to rely on a single case study is related to the nature of the question and by the empirical setting.

In particular, we relied on a single case study, focusing on the car-sharing industry in Milan. Five different Car Sharing Providers (CSP) operating in the city have been involved. After gathering data on the five companies, we enlarged the initial sample, also considering two of the leading Service Aggregators (SA) working in the city, since previous interviews let emerge that they play a crucial role in the business from the user perspective.

The five CSPs start operating in Milan between mid-2013 and early-2017, with many vehicles each that range from 140 to more than 800 . They are in different stages of their growth since some of them approached the market recently and still have a small user base (approximately 10.000 users), while others expanded significantly with more than 350.000 users. The chance to consider this considerable variety under different perspectives (i.e., the number of users, number of cars, years on the market) let us have a more comprehensive view of the industry.

\subsection{Data Gathering and Data Analysis}

Primary and secondary sources have been used for four of the cases regarding the Car Sharing Providers (CSPs), while one of them has been accessible only through secondary sources. Primary sources have been used for the two Service Aggregators (SAs).

The interviews relied on a semi-structured protocol, to have the chance to follow the reasoning of the respondent and to incorporate new questions according to the previous answers (Yin, 2003). The respondents have been contacted according to their ability to provide a strategic view of the company and a longitudinal perspective on the company, Table 1 summarizes the respondents and their role. The interviews took place in Milan, personally or 
through Skype, between March and June 2017. Each company has been interviewed once or twice, and each interview lasted between 25 and 80 minutes. Roughly 100 articles from secondary sources have been considered, regarding both the industry and the specific companies (Table 1).

Through secondary sources, we increased the trustworthiness of the results, leveraging data triangulation (Miles and Huberman, 1984).

\begin{tabular}{r|lll}
\multicolumn{3}{c}{ Respondent role } & \multicolumn{2}{c}{ Secondary Sources } \\
\hline Interviewee 1 & CSP1 & Head of marketing & Institutional websites (Ministero dell'ambiente e \\
Interviewee 2 & CSP2 & Managing director & della tutela del territorio e del mare; Osservatorio \\
Interviewee 3 & CSP3 & Brand manager & Nazionale; ICS - Iniziativa Car Sharing; ANIASA \\
Interviewee 4 & CSP4 & Marketing & - Associazione Nazionale Industria \\
Interviewee 5 & SA1 & Co-Founder & dell'Autonoleggio e Servizi Automobilistici) \\
Interviewee 6 & SA2 & Head of business & Linkiesta; Avvenire; \\
& & CSP5 & Newspapers and magazines (Wired; Il Post; Il \\
& & & Il Sole 24 ore; La Repubblica: Corriere della Sera; \\
& & & La Stampa; Il Messaggero)
\end{tabular}

Table 1 - List of primary and secondary sources

All the interviews have been recorded and transcribed (Saldaña, 2012). Therefore, the transcripts and the secondary sources have been analyzed through a coding process, relying on a deductive approach (Corbin and Strauss 2008). The codebook has been developed leveraging theory-based definitions coming from the literature analysis, bringing to the definition of categories and codes that enabled a proper interpretation of the gathered data. 


\section{Findings}

The presentation is divided into three main sections: i) the view of the respondents regarding car sharing as a case of resistant innovation; ii) their view on the network effect and, and finally, iii) their position regarding coopetition.

\subsection{Car Sharing as a Resistant Innovation}

First of all, all the providers perceived a sense of resistance in proposing their innovation to the market.

Indeed: “Car sharing has been defined as an anthropologic revolution, in some states. Of course, this is a hyperbole, but it surely had to change the Italians' mentality" (interviewed retrieved through secondary sources from a manager in CSP5). Phenomena like car-sharing or scooter sharing define a new stream which "requires a cultural change" (Interviewee3). The change regards the ownership of the car, but it also requires a new kind of relationship and interaction with the car: "Going around in the city you can see a new way to approach the car. People stop in front of them, they take the smartphone out and watch first the car and then the smartphone consequently until the door opens" (Interviewee1).

"They were young; they were the ones that gave us the chance to get known to an increasing slice of the population slowly. Three months after the launch, we had just people in the 20s, now even one in their 70s!" (Interviewee1).

Companies tried to reduce all the entry barriers to the service: they removed the need for a magnetic card to open the car: "The only physical object, besides the smartphone, is the car. There are no other entry or exit barriers to use the service" (Interviewee1).

The other element that helped the company to overcome the significant resistance at the very beginning is the decision to start from big cities: "it is a complementary service in the cities, where there are more public services and people are used to-somehow-not use a private car [...], then it is easier!" (Interviewee1). 


\subsection{The role of Network Effects in the Car Sharing Industry}

The interviews let emerge several dimensions that are relevant to the network effects' perspective.

One of the Service Aggregators claims "It is a market where the demand is stimulated by the offer, this means that the more cars they have available, the more they will use them" (Interviewee6). The statement is widely corroborated by the CSPs, that claim: "The offer side creates the service demand. Structuring the offer, creating the infrastructures, people will use them" (Interviewee2), and "The growth is driven by the number of vehicles that are present in a given area and also from the dimension of the operational area ${ }^{1}$. This requires time, marketing efforts and awareness campaigns" (Interviewee3).

One of the main issues of using car-sharing is the chance not to find an available car in the neighborhood when it is needed. This directly brings to users that rely on different CSPs at the same time: "Users are searching for the service, not for the brand; thus, they are unfaithful. It seems that $50 \%$ of the user-base is multi-brand" (Interviewee3). Companies still want users to be faithful, but at the same time they say: "I care that users come to me first, but at the same time I know that there are some sort of mechanisms that [also using the other providers] will make the general demand increase and all of us will benefit of it" (Interviewee2).

This brought to the birth of different aggregators, satisfying a clear market need: "Aggregators allow [users], through a single app, to see the entire fleet in the city. Then they decide by opportunity, not necessarily by price, but considering the distance as well' (Interviewee1). Moreover, "The customer is unfaithful, he/she will choose one or the other car according to the advantage that would have." (Interviewee3).

The role of Service Aggregators is also seen as something somehow obvious: "We need to think about it, but aggregators in this field are like Booking.com, they are essential"

\footnotetext{
${ }^{1}$ Where the shared cars can travel
} 
(Interviewee3), that may even have a positive impact on the single provider: "We can help them increase the number of users that may have access to their service, providing a bigger user base" (Interviewee5).

\subsection{The role of Coopetition in the Car Sharing Industry}

The industry lived in the last year a second-youth; after years of public investments, in less than five years, five private companies approached the market in Milan and other Italian cities. "If there were just one or two players, probably the demand would not be satisfied, because of the difficulties in covering the city. The cars' availability would not be enough to satisfy the needs of those who need a car in that precise moment" (Interviewee1). Moreover, the competition has been directly considered a plus: "The fact that there were other competitors on the market has been an advantage" (Interviewee2).

Moreover, they still see space for other competitors: "There is space for everybody. There is still plenty of unfilled demand, a demand that needs to be built and to be raised, but it is there" (Interviewee3).

They consider themselves as complementary: "We do not particularly cannibalize each other. We have good relationships, we tried to share not confidential information to let the market grow" (Interviewee3), "We are all needed!" (Interviewee4) and "We complement the offer, we see each other, we talk, there is no grudge, all of us are observing this evolving market" (Interviewee1).

This kind of approach to the competition is considered healthy by all the parties, and brought to the creation of an association: "Almost all the players are enrolled in ANIASA, which is the National Association of Confindustria for Car Sharing. [...] It is the place where we share our perspectives to improve service quality and usage." (Interviewee2). 


\section{Discussion}

\subsection{A Two-Sided Platform perspective on the Car Sharing Industry}

The traditional mechanism that defines a two-sided platform is based on the definition of indirect network externalities (Katz and Shapiro, 1985). This means that a platform links two different groups of customers, enabling a direct transaction (Figure 1, phase 1). An increase in the number of users on the first side leads to the rise of utility for the users of the second side to join the platform and vice versa, defining this kind of externalities (Rochet and Tirole 2003).

The first peculiarity that emerges from the case study is that this mechanism perfectly matches the car-sharing industry, but with a singularity: the second side is owned by the platform provider (as reported in Figure 1, phase 2 through the continuous line on the second side). An increase in the number of users brings to an increased utility in adding an additional car on the second side. The reason why is quite simple: more users bring a higher chance to have more transactions and an additional car increases the potential number of rents. At the same time, increasing the number of cars bring to a higher utility for users that join the platform. Indeed, having more cars increases the chance to have a car close enough to the user that wants to use it, increasing once again the chance to have active transaction through the platform.

The fact that the second side (the cars) is directly "owned" by the platform provider represents an anomaly in the system since traditionally, the two sides are now owned or directly controlled by the platform provider (Rochet and Tirole 2003).

Nevertheless, in the competitive scenario where car-sharing takes place, there are different providers operating on similar platforms. Users are free to move between the different providers, bringing to the chance to be multi-home (Amstrong 2006; Amstrong and Wright 2007). This brings the analysis of this particular kind of two-sided platform to a higher level (Figure 1, phase 3). Having the chance to rely on different platforms, the second side is now 
not directly owned by a platform provider, but open to different players that want to enlarge it. Here we find the first relevant empirical evidence that enhances the literature on two-sided platforms. As stated by the respondent of Interviewee2 "The offer side creates the service demand. Structuring the offer, creating the infrastructures, people will use them", this means that growth in the number of players on the second side would bring to a higher utility for a player that would join the second side. This mechanism is typically described through the definition of direct network externalities (Katz and Shapiro 1985), which is typically described from an end-user perspective (Farrell and Saloner 1986). In this case, we can observe the direct network externalities taking place on the second side, from a provider perspective (Figure 1, phase 4).

Usually, in a two-sided platform, an increase in the number of players being on the second side is necessary to feed the indirect network externalities (e.g., Tucker and Zhang, 2010), but also represents a harsher competition since the users have the chance to choose from a broader array of providers.

This seems to be, at least partially, irrelevant when a two-sided platform is in place to diffuse a resistant innovation (Ram and Sheth 1989). The risk of cannibalization is not taking place at this stage. Indeed there is space for providers that joint their resources to offer a capillary service.

In the end, Service Aggregators become relevant matchmaking the transaction between the two sides, defining a new platform in a more traditional perspective (Figure 1, phase 5). They have the chance to aggregate the offer from the different Car Sharing Providers on the second sides, creating a wider second side, which perfectly matches the traditional definition of two-sided platform leveraging the opportunities of multi-homing (Amstrong 2006, Amstrong and Wright 2007) and making it evident through the creation of a platform that directly allows the multi-home phenomenon. 
1)

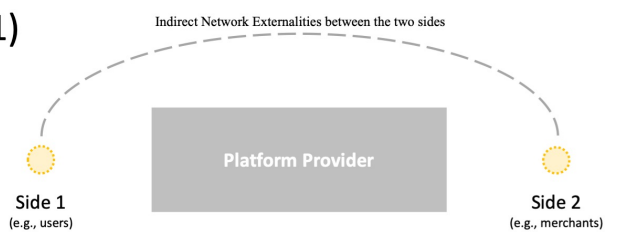

3)

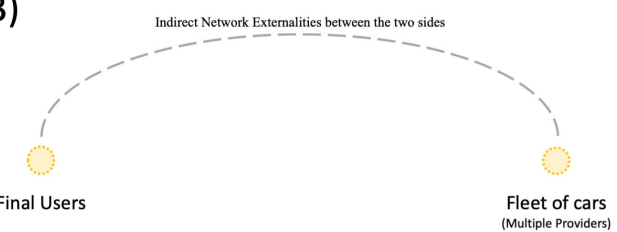

5)

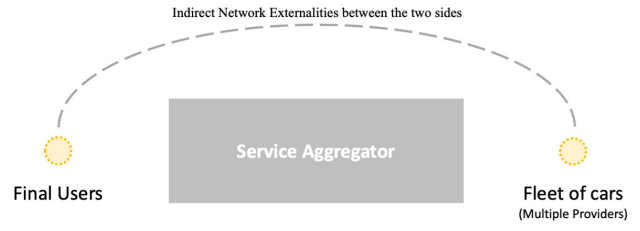

2)

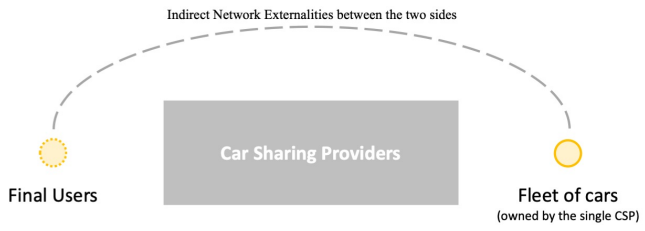

4)



6)

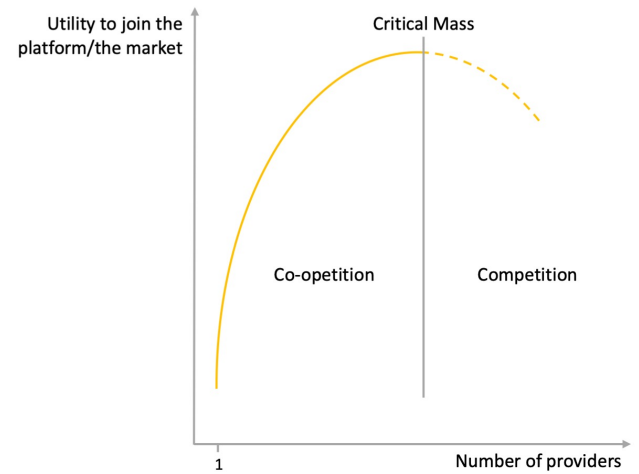

Figure 1 - Car Sharing as a Two-Sided Platform

\subsection{The role of network externalities in disseminating a resistant innovation}

The diffusion of a resistant innovation is a peculiar phenomenon, since trying to go against consumers' current belief is particularly harsh (Ram and Sheth 1989).

A coopetition strategy (Dagnino and Padula, 2002) may be suitable to overcome the difficulties in disseminating a resistant innovation (Garcia et al. 2007). What lack in the literature on resistant innovation is a deeper understanding of how coopetition may enhance the diffusion and dissemination of this kind of innovation. The car-sharing industry provides insights that may be useful to understand this kind of dynamics better.

Therefore, we can see how resistant innovations may have a demand that is mainly driven by the offer, and not from the customers. This means that having different players 
investing in the same resistant innovation may help in overcoming the initial skepticism from the consumers' perspective, especially in an industry where the investments to enlarge the offer are significantly high.

Leveraging on what has been said regarding the two-sided platform in this specific industry, we may see how the utility to join the platform (or in this case the market) from a provider perspective would increase according to the growing number of providers that are already on the market.

This is related to two main dimensions: first, previous entrants worked to reduce the innovation's resistance level, helping consumers to understand it. Moreover, they activate the indirect network externalities that let increase the utility of the users' side in getting on board on the platform.

Service Aggregators, enhancing and making even clearer the chance to implement multi-homing (Amstrong 2006, Amstrong and Wright 2007). The point is not which provider activate a user for the first time since the probability that he/she is going to use also other provider is particularly high.

This kind of reasoning helps us expanding previous research in the field. Indeed, scholars that considered multi-homing effects explained first how they increase the competition level (e.g., Rochet and Tirole 2003) and then how differentiation strategies may be the key to reduce the impact of multi-homing (Gawer and Cusumano 2014). The peculiarities of the analyzed case study let emerge how the different companies pursued differentiation strategies (e.g., using different types of car that may be appealing for different people or pursuing a sustainability strategy using electric cars), but in the end users search for the service: "Users are searching for the service, not for the brand, then he/she is really unfaithful. It seems that $50 \%$ of the userbase is multi-brand"' (Interviewee3). 
Obviously, the competition for a larger market share is still in place, and companies work in different ways also in terms of platform envelopment (Eisenmann et al. 2011), integrating their service with other different offers (e.g., scooter sharing, integration with bike-sharing systems).

Notwithstanding, the implementation of differentiation strategy seems not to have a direct role right now, but in the future. Indeed, we understood that a coopetition based approach at the very beginning might be extremely relevant to overcome the barriers of a resistant innovation since users perceive the service in an undifferentiated way (Figure 1 phase 6). At the same time, due to the network good characteristics previously described, it is plausible that this effect would stop (and even have an adverse effect) once the critical mass is going to be reached, making differentiation strategies relevant once again.

Moreover, the network literature on Multinational Companies let emerge here some more considerations. The growth and diffusion of network companies have implications at various levels, from the corporate to the individual (Gaur et al., 2019). This is evident here, since the network nature of the business impacts on the strategic dynamics among companies. On top of these, for multinational companies, the strength of the network of relationships tends to increase the efficiency and effectiveness of innovation efforts (Nuruzzaman et al., 2019; Pedersen et al., 2019). Similarly, we see how the power of the network created by various companies increases the effectiveness and efficiency of the dissemination process.

Eventually, this research let emerge how a two-sided platform perspective (Rochet and Tirole, 2003) may be useful also for studying and managing industries that may not have all the necessary conditions. Furthermore, it brings different perspectives on some of its traditional assumptions and characteristics. Indeed, the role of direct network externalities should also be considered on the supply side, and not only on the consumers' side (Farrell and Saloner 1986). These externalities, along with multi-homing effects - which have been traditionally considered 
as a possible issue (Armostrong, 2006) - may become leverages to be used to overcome the launching phase (Trabucchi, 2020), implementing a coopetition strategy.

\section{Conclusions}

From a theoretical perspective, this research has a double role. First, it builds on the work of Garcia and colleagues (Garcia et al. 2007) that sees in the coopetition a possible way to facilitate the dissemination process of a resistant innovation. In particular, this research shows how the co-opetitive behavior is useful to trigger the network effects until the reaching of the critical mass. Moreover, it shows how multi-homing (Amstrong 2006, Amstrong and Wright 2007) may be a phenomenon that helps the dissemination process and should be therefore sustained - at least at the beginning - and not stopped. Second, this research enlarges the state of the art of the two-sided platform literature (e.g., Rochet and Tirole 2003), focusing on the role of direct network externalities (Katz and Shapiro 1985) on the second side and on the role the indirect network externalities may play even in the absence of an intermediary platform or when the platform provider wholly owns the second side. Looking at network businesses, it also links the literature on global networks (e.g., Gaur et al., 2019; Nuruzzaman, et al., 2019) to different kinds of businesses, such as two-sided platforms.

Finally, from a managerial perspective, this research sheds light on the role of the coopetition strategies, which may play a significant role in the first phase of the dissemination process. Dealing with resistant innovation, instead of fighting new entrants, a proactive and collaborative behavior may be suitable to help the users accepting the required change in their behavior and eventually to understand the potential value of the innovation itself.

From a practitioner perspective, this research may even push some other reflections. Indeed, one of the key peculiarities of this industry is that behind the Car Sharing Providers, there are often big corporations and not newly born start-ups that may have issues in finding considerable investments to scale up. Therefore, the chance to leverage a coopetition strategy 
to reach the network effects is not a matter of not having enough or the rights complementary assets (Teece, 1986), it is a matter of the chance to overcome a resistance barrier in the consumers' behaviors leveraging on physical core assets that cannot be outsourced as in other cases of sharing economy (Ndubisi et al., 2016). Therefore, these considerations may help those industries where the diffusion and dissemination processes are somehow blocked, and companies are trying to act in a winner-takes-all perspective.

This paper is not free of limitations. First, it is based on a small and biased sample that considers only the players of one industry in a single city. This would lead to the first possible further research avenue, considering other fields or other countries, to understand the role that those dynamics may play on the findings.

Moreover, this is exploratory research based on a qualitative analysis that brings to qualitative consideration. The chance to consider a more comprehensive amount of data, eventually in a longitudinal perspective, may be useful to understand how the behaviors of companies that work in similar environments may or may not change after reaching the critical mass and when the network effects start flourishing.

\section{References}

Ali, A., \& Matsuno, K. (2018). Mediating roles of capabilities between R\&D-marketing integration and business performance. Journal of Asia Business Studies, 12(1), 81-98.

Artusi, F. and Bellini, E. (2020), "Design and the customer experience: the challenge of embodying new meaning in a new service", Creativity and Innovation Management.

Amit, R., \& Han, X. (2017). Value creation through novel resource configurations in a digitally enabled world. Strategic Entrepreneurship Journal.

Arbussa, A., Bikfalvi, A., \& Marquès, P. (2017). Strategic agility-driven business model renewal: The case of an SME. Management Decision.

Armstrong, M. (2006). Competition in two-sided markets. RAND Journal of Economics, 37(3), 668-691. 
Armstrong, M., \& Wright, J. (2007). Two-sided markets, competitive bottlenecks and exclusive contracts. Economic Theory, 32(2), 353-380.

Beck, R., Beimborn, D., Weitzel, T., \& König, W. (2008). Network effects as drivers of individual technology adoption: Analyzing adoption and diffusion of mobile communication services. Information Systems Frontiers, 10(4), 415-429.

Bowser, J. (2001). Strategic coopetition: The value of relationships in the networked economy. IBM Global Services, New York,

Bugador, R. (2019). The global expansion of UBER in ASIAN markets. International J ournal of Supply Chain Management 8(2), 569.

Claudy, M. C., Garcia, R., \& O’Driscoll, A. (2015). Consumer resistance to innovation-a behavioral reasoning perspective. Journal of the Academy of Marketing Science, 43(4), 528-544.

Cohen, B., \& Kietzmann, J. (2014). Ride on! mobility business models for the sharing economy. Organization \& Environment, 27(3), 279-296.

Corbin, J., \& Strauss, A. (2008). Basics of qualitative research: Techniques and procedures for developing grounded theory.

Dagnino, G. B., \& Padula, G. (2002). Coopetition strategy: A new kind of interfirm dynamics for value creation. Innovative Research in Management, European Academy of Management (EURAM), Second Annual Conference, Stockholm, may, 9

Dittrich, K., \& Duysters, G. (2007). Networking as a means to strategy change: The case of open innovation in mobile telephony. Journal of Product Innovation Management, 24(6), 510-521.

Downes, L., \& Nunes, P. (2014). Big bang disruption: Strategy in the age of devastating innovation Penguin.

Dyer Jr, W. G., \& Wilkins, A. L. (1991). Better stories, not better constructs, to generate better theory: A rejoinder to eisenhardt. Academy of Management Review, 16(3), 613-619.

Economides, N., \& Himmelberg, C. P. (1995). Critical mass and network size with application to the US fax market.

Eisenmann, T. R., Parker, G., \& Van Alstyne, M. W. (2010). Platform envelopment.

Eisenhardt, K. (1989). Building theories from case study research. Academy of Management Review. 14 (4), $532-550$.

Farrell, J., \& Saloner, G.(1986). Installed base and compatibility: Innovation, product preannouncements, and predation. The American Economic Review, 940-955. 
Frattini, F., Dell'Era, C., \& Rangone, A.(2013). Launch decisions and the early market survival of innovations: An empirical analysis of the Italian mobile Value-Added services (VAS) industry. Journal of Product Innovation Management, 30(S1), 174-187.

Garcia, R., \& Calantone, R. (2002). A critical look at technological innovation typology and innovativeness terminology: A literature review. Journal of Product Innovation Management, 19(2), 110-132.

Garcia, R., Bardhi, F., \& Friedrich, C. (2007). Overcoming consumer resistance to innovation. MIT Sloan Management Review, 48(4), 82.

Gaur, A. S., Kumar, V., \& Singh, D. (2014). Institutions, resources, and internationalization of emerging economy firms. Journal of World Business, 49(1), 12-20.

Gaur, A. S., Ma, H., \& Ge, B. (2019). MNC strategy, knowledge transfer context, and knowledge flow in MNEs. Journal of Knowledge Management.

Gawer, A., \& Cusumano, M. A. (2014). Industry platforms and ecosystem innovation. Journal of Product Innovation Management, 31(3), 417-433. doi:10.1111/jpim.12105

Greenhalgh, T., Robert, G., Macfarlane, F., Bate, P., \& Kyriakidou, O. (2004). Diffusion of innovations in service organizations: Systematic review and recommendations. The Milbank Quarterly, 82(4), 581-629.

Hagiu, A., \& Wright, J. (2015). Multi-sided platforms. International Journal of Industrial Organization, 43, $162-$ 174.

Hultink, E. J., Griffin, A., Hart, S., \& Robben, H. S. (1997). Industrial new product launch strategies and product development performance. Journal of Product Innovation Management, 14(4), 243-257.

Huotari, P., Järvi, K., Kortelainen, S., \& Huhtamäki, J. (2017). Winner does not take all: Selective attention and local bias in platform-based markets. Technological Forecasting and Social Change, 114, 313-326. doi:10.1016/j.techfore.2016.08.028

Katz, M. L., \& Shapiro, C. (1985). Network externalities, competition, and compatibility. The American Economic Review, 75(3), 424-440.

Libert, B., Beck, M., \& Wind, J. (2016). The network imperative: How to survive and grow in the age of digital business models Harvard Business Press Review.

Lunnan, R., \& McGaughey, S. L. (2019). Orchestrating international production networks when formal authority shifts. Journal of World Business, 54(5), 101000. 
Maharjan, M. P., \& Sekiguchi, T. (2017). Human resource management practices of japanese companies in india: Dealing with the transfer-adaptation dichotomy. Journal of Asia Business Studies, 11(3), 323-341.

Magistretti, S., Dell'Era, C., \& Verganti, R. (2020). Look for New Opportunities in Existing Technologies: Leveraging Temporal and Spatial Dimensions to Power Discovery. ResearchTechnology Management, 63(1), 39-48.

Miles, M. B., \& Huberman, A. M. (1984). Drawing valid meaning from qualitative data: Toward a shared craft. Educational Researcher, 13(5), 20-30.

Ndubisi, N. O., Ehret, M., \& Wirtz, J. (2016). Relational governance mechanisms and uncertainties in nonownership services. Psychology \& Marketing, 33(4), 250-266.

Nuruzzaman, N., Gaur, A. S., \& Sambharya, R. B. (2019). A microfoundations approach to studying innovation in multinational subsidiaries. Global Strategy Journal, 9(1), 92-116.

Pedersen, T., Soda, G., \& Stea, D. (2019). Globally networked: Intraorganizational boundary spanning in the global organization. Journal of World Business, 54(3), 169-180.

Ram, S. (1989). Successful innovation using strategies to reduce consumer resistance: An empirical test. Journal of Product Innovation Management, 6(1), 20-34.

Rochet, J. -., \& Tirole, J. (2003). Platform competition in two-sided markets. Journal of the European Economic Association, 1(4), 990-1029.

Rogers, E. M. (2010). Diffusion of innovations. Simon and Schuster.

Saldaña, J. (2015). The coding manual for qualitative researchers Sage.

Schiller, T., Scheidl, J., \& Pottebaum, T. (2017). Car Sharing in Europe. Business Models, National Variotons and Upcoming Disruptors. Monitor Deloitte. Issued 6/2017.

https://www2.deloitte.com/content/dam/Deloitte/de/Documents/consumer-industrial-products/CIPAutomotive-Car-Sharing-in-Europe.pdf

Siggelkow, N. (2007). Persuasion with case studies. Academy of Management Journal, 50(1), 20-24.

Singh, D. A., \& Gaur, A. S. (2013). Governance structure, innovation and internationalization:

Evidence from india. Journal of International Management, 19(3), 300-309.

Szmigin, I., \& Foxall, G. (1998). Three forms of innovation resistance: The case of retail payment methods. Technovation, 18(6), 459-468. 
Trabucchi, D. (2020). Let's get a two-sided platform started: Tactics to solve the chicken and egg paradox. Journal of Business Ecosystems (JBE), 1(1), 63-77.

Trabucchi, D., \& Buganza, T. (2020). Fostering digital platform innovation: From two to multi-sided platforms. Creativity and Innovation Management, 29(2), 345-358.

Treacy, M., \& Wiersema, F. (2007). The discipline of market leaders: Choose your customers, narrow your focus, dominate your market Basic Books.

Tucker, C., \& Zhang, J. (2010). Growing two-sided networks by advertising the user base: A field experiment. Marketing Science, 29(5), 805-814. doi:10.1287/mksc.1100.0560

Yin, R. K. (2003). Case study research: Design and methods. thousands oaks. International Educational and Professional Publisher.

\section{Acknowledgments}


The authors would like to thank all the practitioners that have been interviewed and dedicated their time to this research. Moreover, the authors would like to acknowledge Francesca Decandia and Laura Anna Russo, who provided a valuable contribution in the early stages of this research. 